\title{
KARAKTER FENOTIPE DAN GENOTIPE IKAN MAS “MERAH MENYALA” NAJAWA DARI CANGKRINGAN, JOGJAKARTA SERTA POTENSI EKONOMISNYA
}

\author{
Estu Nugroho"), Dwijo Priyanto"), Hery Sulistio Hermawan"), Sunaryo", dan Andung Santoso Prihadi" \\ ") Pusat Penelitian dan Pengembangan Perikanan Budidaya \\ Jl. Ragunan 20, Pasar Minggu, Jakarta Selatan 12540 \\ E-mail: engroho@yahoo.com \\ ${ }^{\circ)}$ Dinas Kelautan dan Perikanan Provinsi Daerah Istimewa Jogjakarta
}

\begin{abstract}
ABSTRAK
Plasma nutfah ikan merupakan kekayaan sumber daya yang dapat dimanfaatkan untuk pengembangan budidaya perikanan. Salah satu jenis plasma nutfah yang layak untuk dikembangkan adalah ikan mas merah Najawa. Penelitian ini bertujuan untuk mengetahui karakter fenotipe dan genotipe ikan mas merah Najawa dan potensi ekonomisnya dalam usaha budidaya. Ikan mas ini mempunyai kualitas warna merah yang sangat menyala, berbeda dengan jenis ikan mas dari daerah lainnya di Indonesia. Pengembangan jenis ikan ini akan lebih banyak dimanfaatkan oleh daerah-daerah yang mempunyai preferensi pada ikan warna cerah dibandingkan daerah dengan kesukaan pada ikan dengan warna gelap. Di antaranya adalah daerah Sumatera Barat, Sumatera Utara, dan Daerah Istemewa Jogjakarta. Sampai saat ini hasil seleksi warna telah menghasilkan keturunan dengan proporsi $87,1 \%$ mempunyai warna merah mulus, $2,7 \%$ warna albino dan sisanya $10,2 \%$ mempunyai warna merah berbintik hitam. Identifikasi morfometrik dengan menggunakan metode Truss Network menunjukkan adanya perbedaan pada parameter C (jarak kepala dan sirip dada), F (jarak sirip punggung dan sirip perut), dan $\mathrm{M}$ (panjang standar) dibandingkan dengan ikan mas Majalaya. Karakterisasi secara genetik dengan menggunakan marker molekuler RAPD dengan 6 primer menunjukkan perbedaan secara genetik yang nyata dibandingkan beberapa varietas ikan mas yang banyak digunakan oleh masyarakat yaitu ikan mas Rajadanu, Majalaya, Wildan, Sinyonya, dan Sutisna. Ikan mas Najawa mempunyai tingkat keragaman 0,1513, sedangkan 5 jenis ikan mas lainnya yang mempunyai tingkat keragaman antara 0,2120 (Majalaya) hingga 0,2747 (Wildan).
\end{abstract}

KATA KUNCI : ikan mas, merah menyala, Jogjakarta

ABTRACT: $\quad$ Phenotype and genotype characters of red lit Najawa from Cangkringan Yogjakarta and its economic potential. By: Estu Nugroho, Dwijo Priyanto, Hery Sulistio Hermawan, Sunaryo, and Andung Santoso Prihadi

Fish germplasm is a wealth of resources that can be utilized for the development of aquaculture. One type of germplasm that deserves to be developed is a red common carp NAJAWA. The objective of this researh was to observe the phenotype and genotype characters of red lit Najawa carp and to evaluate its economic potential in culture. This common car fish has a quality that is very lit red color, in contrast to the type of carp from other areas in Indonesia. The development of these fish will be more widely used by the regions that have a preference on color fish "brighter" than areas with a preference for fish with a dark color. Among them is the area of West Sumatra, North Sumatra and Regional privileges Jogjakarta. Until now, the color selection results have produced off spring with the proportion of $87.1 \%$ have a smooth red color, $2.7 \%$ albino color and the remaining $10.2 \%$ have a red color black spots. Truss morphometric analysis showed that there is significant different on the length of pectoral fin and head $(C)$, the length of dorsal fin and abdomen fin (F), standar length (M) of Najawa carp compare to majalaya carp. There is also significant different genetically among Najawa, Rajdanu, Majalay, Wildan, Sinyonya, Sutina carp revealed by RAPD markers using 6 primers. Najawa carp has the lowest genetic variance with haplotipe diversity of 0.1513. While five others were range of 0.2120 (Majalaya) to 0.2747 (Wildan).

KEYWORDS: $\quad$ common carp, red lit, Jogjakarta

\section{PENDAHULUAN}

Ikan mas termasuk salah satu jenis ikan air tawar ekonomis penting di Indonesia karena mempunyai sifat yang mudah dipelihara dan dikembangkan dengan persyaratan tertentu. Di alam ikan mas hidup di perairan sungai, danau maupun genangan air lainnya yang berada pada ketinggian 150-600 $\mathrm{m} \mathrm{dpl}$, dengan suhu air berkisar $20^{\circ} \mathrm{C}-25^{\circ} \mathrm{C}$, pH air yang berada pada kisaran 6,5-8,5, sedangkan kandungan oksigen terlarut lebih dari 3 mg/L (Kartamiharja, 1998). 


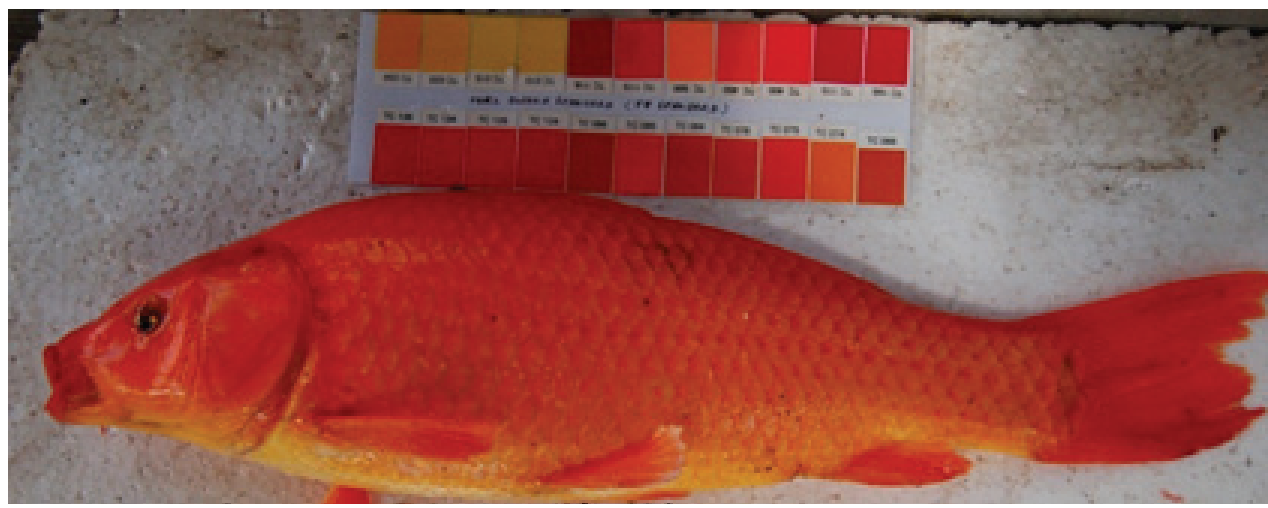

Gambar 1. Perbandingan warna ikan mas Najawa dengan Toca Colour Standard

Figure 1. Colour of Najawa carp compared with Toca Colour Standard

Ikan introduksi ini mulai masuk ke Indonesia sejak tahun 1920-an, berasal dari Cina, Eropa, Taiwan, dan Jepang. Beberapa strain ikan mas yang umum ditemukan di Indonesia antara lain Punten, Sinyonya, Majalaya, Karper Kaca, Karper Merah, Karper Taiwan, Karper Koi, Kumpay atau Karper Kaca Sirip Panjang, Domas, dan Kancra domas (Hardjamulia \& Suseno, 1976; Sumantadinata, 1995). Penyebaran ikan mas di Indonesia meliputi daerah Aceh, Sumatera Barat, Jambi, Bengkulu, Jawa Barat, Jawa Tengah, Jawa Timur, Sulawesi Selatan, dan Sulawesi Selatan (Hardjamulia, 1998).

Di daerah Jogjakarta, khususnya sekitar aliran sungai dari lereng gunung Merapi yaitu daerah Cangkringan terdapat satu jenis ikan mas yang mempunyai performa warna yang khas yaitu merah menyala. Jenis ikan mas "cangkringan" mulai dikoleksi sebagai bahan plasma nutfah pada tahun 1970 yaitu sebanyak 40 ekor induk jantan dan 32 ekor induk betina (DKP Jogjakarta, 2013). Kemudian ikan ini dijadikan bahan untuk kegiatan pemuliaan yang dimulai dengan proses domestikasi yang kemudian dilanjutkan dengan program seleksi. Pada tahun 2013, jenis ikan mas ini telah lulus dalam pengujian sebagai varietas yang layak untuk dirilis atau diedarkan sebagai kandidat budidaya, dan diusulkan dengan nama ikan mas merah Najawa (mina jogja istimewa). Penelitian ini bertujuan untuk mengetahui karakter fenotipe dan genotipe ikan mas merah Najawa serta potensi ekonomisnya dalam usaha budidaya.

\section{BAHAN DAN METODE}

Ikan mas yang diamati adalah ikan mas yang telah dikoleksi dan dijadikan bahan awal untuk program pemuliaan dari Balai Budidaya Ikan Air Tawar
Cangkringan, Dinas Kelautan dan Perikanan Provinsi Daerah Istimewa Jogjakarta pada tahun 2013.

Parameter yang diamati meliputi kualitas warna secara visual dengan menggunakan pembanding standar kertas warna (Toca Colour Standar), bentuk badan dengan menggunakan analisis truss-morfometrik, serta data genetik dengan menggunakan marka molekuler RAPD (Random Amplified Polymorphism DNA) (DKP Jogjakarta, 2013). Selain itu, sebagai data pendukung pengembangan budidaya ikan mas ini berupa analisis usaha pada tingkat pembenihan dan pembesaran.

\section{HASIL DAN BAHASAN}

\section{Keistimewaan Ikan Mas Najawa}

Sesuai dengan penampakan secara visual, ikan mas Najawa mempunyai sifat yang khas yaitu warna badan yang "merah menyala" berbeda dengan jenis ikan mas umumnya yang beredar di daerah lainnya. Kualitas warna merah ini dikategorikan menjadi dua yaitu untuk daerah bagian atas mulai dari kepala hingga pangkal ekor mempunyai standar warna no. TC 125 jika diukur dengan Toca colour Standard. Sedangkan daerah bagian bawah mulai kepala hingga pangkal ekor berwarna agak muda dengan standar warna no. TC 074. Di antara kedua bagian punggung dan perut ini terdapat gradasi warna (Gambar 1).

Setelah sekitar 40 tahun program program seleksi warna ikan mas dilakukan maka warna merah ikan NAJAWA yang dihasilkan pada turunannya mempunyai proporsi sebagai berikut: $87,1 \%$ mempunyai warna merah mulus, $2,7 \%$ warna albino dan sisanya $10,2 \%$
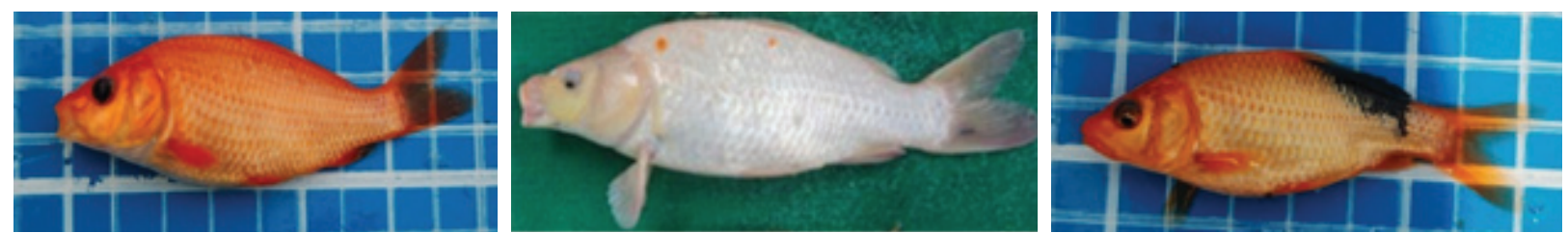

Gambar 2. Sebaran warna ikan mas merah Najawa

Figure 2. Colours of Najawa red carp 


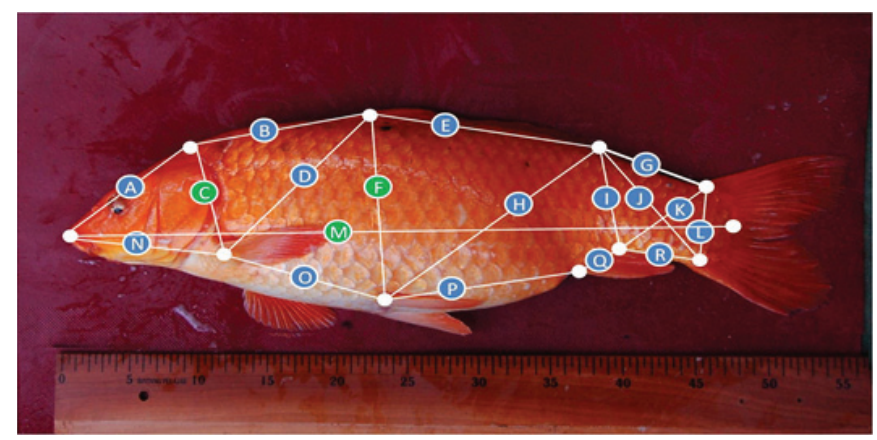

Gambar 3. Truss network ikan mas Najawa

Figure 3. Najawa carp truss network

mempunyai warna merah berbintik hitam (Gambar 2). Tahap perubahan warna ikan mas merah Najawa dimulai dari stadia larva sampai benih umur 60 hari berwarna merah kekuningan, selanjutnya berangsur-angsur berubah warna menjadi merah menyala hingga dewasa.

Secara morfometri ikan mas Najawa jantan memiliki perbandingan proporsi tubuh lebih kecil dibandingkan dengan betina. Pengamatan pada beberapa parameter tubuh yang diukur menunjukkan perbedaan yang signifikan antara ikan jantan dan betina yaitu pada panjang total, tinggi badan, dan lebar badan. Identifikasi morfometrik ikan mas Najawa dilakukan dengan menggunakan metode Truss Network. Hasil pengukuran terhadap morfometrik ikan mas Najawa menunjukkan adanya perbedaan pada parameter C (Jarak kepala dan sirip dada), F (Jarak sirip punggung dan sirip perut), dan M (Panjang standar) dibandingkan dengan ikan mas Majalaya sebagaimana ditunjukkan pada Gambar 3.

\section{Karakteristik Genetik}

Seirama dengan performa kualitas warnanya, karakterisasi secara genetik dengan menggunakan marker molekuler (RAPD dengan 6 primer, OPA18, OPB10, OPG5, OPZ2, OPZ5, dan OPZ13) menempatkan ikan mas NAJAWA mempunyai perbedaan secara genetik yang nyata dibandingkan beberapa varietas ikan mas yang banyak digunakan oleh masyarakat yaitu ikan mas Rajadanu, Majalaya, Wildan, Sinyonya, dan Sutisna (DKP Jogjakarta, 2013). Ikan mas Najawa mempunyai tingkat keragaman yang terkecil yaitu 0,1513 ; dibandingkan 5 jenis ikan mas lainnya yang mempunyai tingkat keragaman antara 0,2120 (Majalaya) hingga 0,2747 (Wildan). Hal ini menunjukkan ikan mas Najawa mempunyai kestabilan yang lebih tinggi sebagai galur murni dibandingkan lima jenis ikan mas lainya.

Hasil analisa terhadapjarakgenetikNei menunjukkan bahwa ikan mas Najawa mempunyai kekerabatan yang terjauh atau berada dalam kelompok terpisah dari grup lainnya yang beranggotakan kelima jenis ikan mas lainnya. Ikan mas Rajadanu berkerabatan dekat dengan Majalaya, ikan mas Wildan berkerabatan dekat dengan Sinyonya dan Sutisna. Hal ini mengindikasikan bahwa jenis ikan mas Najawa mempunyai sifat fenotif yaitu warna yang berbeda dan telah diturunkan kepada turunannya secara terus-menerus sehingga menjadi satu varietas sendiri yang berbeda.

\section{Potensi Bisnis}

Memperhatikan warna merahya yang khas, tidak menutup kemungkinan ikan mas Najawa mempunyai peluang yang cukup baik sebagai komoditas budidaya. Secara garis besar pada bidang pembenihan yang dilakukan di Jogjakarta, penggunaan ikan mas Najawa mempunyai nila $\mathrm{R} / \mathrm{C}$ ratio yang cukup besar yaitu; 1,95 yang berarti layak untuk diusahakan secara bisnis. Berikut ini analisa usaha bidang pembenihan ikan Najawa secara ringkas. (Tabel 1)

Tabel 1. Analisis usaha dalam bidang pembenihan ikan mas Najawa Table 1. Business analysis of Najawa carp breeding

\begin{tabular}{|c|c|c|}
\hline Uraian (Items) & \multicolumn{2}{|c|}{ Biaya (Cost) } \\
\hline Biaya tetap & $\mathrm{Rp}$ & $215.052,-$ \\
\hline \multicolumn{3}{|l|}{ Biaya variabel: } \\
\hline - Persiapan kolam & $\mathrm{Rp}$ & $356.700,-$ \\
\hline - Pakan & $\mathrm{Rp}$ & $132.000,-$ \\
\hline - $\quad$ Pupuk & $\mathrm{Rp}$ & $180.000,-$ \\
\hline Total Biaya (TC) & $\mathbf{R p}$ & $883.752,-$ \\
\hline Penerimaan total $(\mathrm{TR}) \mathrm{Rp} 20,-\times 86.200$ ekor & Rp & 1.724.000 ,- \\
\hline Penerimaan bersih $(\pi)$ & Rp & $840.248,-$ \\
\hline \multicolumn{3}{|l|}{ Total revenue (TR) - Total cost } \\
\hline $\mathrm{R} / \mathrm{C}$ rasio $(R / C$ ratio $)$ & & 1,95 \\
\hline
\end{tabular}


Tabel 2. Analisis usaha pembesaran ikan mas Najawa

Table 2. Business analysis of Najawa carp enlargement

\begin{tabular}{|c|c|c|c|}
\hline \multicolumn{2}{|r|}{ Uraian (Items) } & \multicolumn{2}{|c|}{ Biaya (Cost) } \\
\hline Biaya tetap & & $\mathrm{Rp}$ & - \\
\hline \multicolumn{4}{|l|}{ Biaya variabel: } \\
\hline - Benih & & $\mathrm{Rp}$ & 1.500.000 ,- \\
\hline - Tenaga kerja & & $\mathrm{Rp}$ & 413.600 ,- \\
\hline - Pelet & & $\mathrm{Rp}$ & 17.718.750 , \\
\hline - Pupuk & & $\mathrm{Rp}$ & 100.000 \\
\hline Total & & $\mathrm{Rp}$ & - \\
\hline Penerimaan total & & & \\
\hline Jumlah produksi x harga & $1.125 \mathrm{~kg} \times \mathrm{Rp} 23.000,-$ & Rp & 25.875.000 ,- \\
\hline $\begin{array}{l}\text { Penerimaan bersih }(\pi) \\
\mathrm{R} / \mathrm{C} \text { rasio }(R / C \text { ratio })\end{array}$ & Rp 25.875.000,- - Rp 19.770.889,- & $\mathrm{Rp}$ & $\begin{array}{l}6.104 .111,- \\
1,31\end{array}$ \\
\hline
\end{tabular}

Bidang pembesaran ikan mas Najawa mempunyai nila R/C Ratio sebesar 1,3 yang berarti layak untuk dijadikan sebagai usaha bisnis. Analisa Usaha bidang pembesaran ikan mas Najawa secara ringkas dapat dilihat pada Tabel 2 .

\section{KESIMPULAN}

Ikan mas Najawa memiliki kekhasan warna merah menyala dan karakteristik genetik yang berbeda dengan ikan mas lainnya (Majalaya, Rajadanu, Sinyonya, Sutisna, dan Wildan). Domestikasi ikan mas Najawa yang dilakukan oleh Balai Pengembangan Tekonologi Kelautan dan Perikanan Dinas Kelautan dan Perikanan DIY bertujuan agar ikan mas Najawa dapat dimanfaatkan oleh Unit Pembenihan Rakyat dan Kelompok Pembudidaya Ikan secara lebih luas dengan pengawasan dan kontrol dari Pemerintah. Di samping itu, merupakan salah satu sumber plasma nutfah yang dapat digunakan untuk kegiatan pemuliaan ikan mas.

\section{DAFTAR ACUAN}

Dinas Kelautan dan Perikanan (DKP) Jogjakarta. (2013). Naskah Permohonan Pelepasan Strain Ikan Mas Merah Cangkringan. Jogjakarta, $87 \mathrm{hlm}$.

Hardjamulia, A., \& Suseno, D. (1976). Some aspect of freshwater fish genetics. agriculture genetic workshop. University Padjadjaran. Bandung, 14 pp.

Hardjamulia, A. (1998). Characterization and evaluation of four strains of common carp in Indonesia. Consultan and Evaluation Meeting of Seed Production Program at Sukabumi. Directorate General of Fisheries. Jakarta, 15 pp.

Kartamihardja, E.S. (1998). Analisis penyebab kematian ikan secara massal dalam budidaya karamba jaring apung di Danau Maninjau, Sumatera Barat. Laporan Balitkanwar. $10 \mathrm{hlm}$.

Sumantadinata, K. (1995). Present state of common carp (Cyprinus carpio) stocks in Indonesia. Aquaculture, 129, 205-209. 